\title{
BMJ Open Impact of aspirin use on clinical outcomes in patients with vasospastic angina: a systematic review and meta- analysis
}

\author{
Yaowang Lin (D) , ${ }^{1}$ Yang Chen, ${ }^{2}$ Jie Yuan, ${ }^{1}$ Haiyan Qin $(D),{ }^{3}$ Shaohong Dong, ${ }^{1}$ \\ Qiuling Chen (1) ${ }^{4}$
}

To cite: Lin Y, Chen Y, Yuan J, et al. Impact of aspirin use on clinical outcomes in patients with vasospastic angina: a systematic review and meta-analysis. BMJ Open 2021;11:e048719. doi:10.1136/ bmjopen-2021-048719

- Prepublication history for this paper is available online. To view these files, please visit the journal online (http://dx.doi. org/10.1136/bmjopen-2021048719).

Received 05 January 2021 Accepted 05 July 2021
Check for updates

(c) Author(s) (or their employer(s)) 2021. Re-use permitted under CC BY-NC. No commercial re-use. See rights and permissions. Published by BMJ.

For numbered affiliations see end of article.

Correspondence to Shaohong Dong; xnkdsh@yeah.net and Qiuling Chen;

szchenqiuling@126.com

\section{ABSTRACT}

Objectives The use of aspirin to prevent cardiovascular disease in vasospastic angina (VSA) patients without significant stenosis has yet to be investigated. This study aimed to investigate the efficacy of aspirin use among VSA patients.

Design Systematic review and meta-analysis.

Data sources PubMed, Web of Science and Cochrane Central Register of Controlled Trials were searched for relevant information prior to October 2020.

Eligibility criteria for selecting studies Aspirin use versus no aspirin use (placebo or no treatment) among VSA patients without significant stenosis.

Data extraction and synthesis Two investigators extracted the study data. ORs and 95\% Cls were calculated and graphed as forest plots. The NewcastleOttawa Quality Assessment Scale tool and Begg's funnel plot were used to assess risk of bias.

Results Four propensity-matched cohorts, one retrospective analysis and one prospective multicentre cohort, in total comprising 3661 patients (aspirin use group, $\mathrm{n}=1695$; no aspirin use group, $\mathrm{n}=1966$ ) were included in this meta-analysis. Aspirin use and the incidence of major cardiovascular adverse events with follow-up of 1-5 years were not significantly correlated (combined OR=0.90, 95\% Cl: 0.55 to $1.68, p=0.829$, $\mathrm{I}^{2}=82.2 \%$; subgroup analysis: $\mathrm{OR}=1.09,95 \% \mathrm{Cl}$ : 0.81 to $1.47, I^{2}=0 \%$ ). No significant difference was found between aspirin use and the incidence of myocardial infarction (OR=0.62, 95\% Cl: 0.09 to $4.36, p=0.615, I^{2}=73.8 \%$ ) or cardiac death $(\mathrm{OR}=1.73,95 \% \mathrm{Cl}: 0.61$ to $4.94, \mathrm{p}=0.444$, $\mathrm{I}^{2}=0 \%$ ) during follow-up.

Conclusion Aspirin use may not reduce the risk of future cardiovascular events in VSA patients without significant stenosis.

PROSPERO registration number CRD42020214891.

\section{INTRODUCTION}

Coronary spasm characterised by vasospastic angina (VSA) is one cause of ischaemia in a non-obstructive coronary artery. ${ }^{1}{ }^{2}$ VSA patients who also suffer from endothelial dysfunction or coronary atherosclerosis commonly use aspirin, ${ }^{34}$ as per the guidelines of the European Society of Cardiology,
Strengths and limitations of this study

- This is the first meta-analysis to evaluate the impact of aspirin use on clinical outcomes in patients with vasospastic angina.

- The therapeutic drug used in the study by Mori (2020) is an antiplatelet drug that includes aspirin and P2Y12 inhibitors.

- The limitations inherent to multicentre observational studies performed in both retrospective and prospective manners may have affected data analysis.

- The conclusions of this study should be verified with randomised controlled trials with a larger sample size.

for the management of chronic stable angina and acute coronary syndromes. ${ }^{56}$

The ASCEND study showed that the use of low-dose aspirin leads to a lower risk of serious vascular events $(8.5 \%$ vs $9.6 \%$; $\mathrm{p}=0.01)$ compared with placebo among persons with diabetes in primary treatment, but the absolute benefits of aspirin are largely counterbalanced by the bleeding hazard $(4.1 \%$ vs $3.2 \%$; $\mathrm{p}=0.003) .{ }^{7}$ The ARRIVE study also suggested that aspirin use may result in a higher incidence of gastrointestinal bleeding $(0.97 \%$ vs $0.46 \% ; \mathrm{p}=0.0007)$ or overall incidence of treatment-related adverse events $(16.75 \%$ vs $13.54 \%$; $\mathrm{p}<0.0001)$ compared with control groups. ${ }^{8}$ Owing to the latest controversy and reduced usage of aspirin in preventing cardiovascular events, ${ }^{9} 10$ aspirin's efficiency in VSA patients without significant stenosis has not yet been reported. ${ }^{11-16}$ Therefore, this meta-analysis was designed to assess the correlation between aspirin use and cardiovascular events and cardiac death among VSA patients during long-term follow-up. 


\section{MATERIALS AND METHODS}

\section{Search strategy}

A comprehensive search of PubMed, Web of Science and Cochrane Central Register of Controlled Trials databases for related research articles conducted before October 2020 was conducted to gather data. The keywords were 'vasospastic angina', 'coronary vasospasms', 'vasospasm', 'variant angina', 'Prinzmetal's variant angina', 'spastic coronary angina', 'coronary artery spasm,' as well as 'aspirin' and 'antiplatelet therapy'. Certain additionalrelated publications, such as review articles and editorials, were also assessed.

\section{Patient and public involvement}

Study participants met the eligibility criteria as outlined above. All included patients were diagnosed with epicardial coronary vasospasms by provocation test. Participants and other members of the public were not involved in the recruitment, design, conduct, reporting, or dissemination of this study.

\section{Study selection and data extraction}

The patient inclusion criteria were as follows: (i) diagnosed with VSA on provocation test, (ii) absence of significant stenosis $(\leq 50 \%)$, (iii) the treatment group was administered oral aspirin and the control group received no aspirin or placebo and (iv) articles published in English. The exclusion criteria were as follows: significant stenosis $(\geq 50 \%)$, intravenous aspirin, case report and case series. The study data were independently extracted by two investigators, namely Lin and Chen, using predefined extraction forms; any conflict was resolved by a third reviewer.

\section{Data analysis and risk of bias assessment}

Major cardiovascular adverse events (MACE) were the primary endpoints, while myocardial infarction (MI) and cardiac death during follow-up were the secondary endpoints. MACE have been described as cardiac death, acute coronary syndrome and hospitalisation due to unstable angina, percutaneous coronary intervention, symptomatic arrhythmia, appropriate implantable cardioverter defibrillator and shock. The Newcastle-Ottawa Quality Assessment Scale (NOS) tool was utilised to assess the risk of bias, and Begg's funnel plot was used to evaluated publication bias.

\section{Statistical analysis}

STATA software (V.14.0; StataCorp, College Station, TX, USA) was used for the meta-analysis. MACE (primary endpoints) and MI and cardiac death (secondary endpoints) were evaluated as combined ORs with 95\% CIs. Heterogeneity between studies was derived using the $\mathrm{I}^{2}$ statistic. If $\mathrm{I}^{2}>50 \%$, the random effect model was used to assess heterogeneity; if $\mathrm{I}^{2}<50 \%$, the fixed effect model was utilised to evaluate heterogeneity. Subgroups were studied to reduce the heterogeneity if $\mathrm{I}^{2}>50 \%$. P values $<0.05$ were considered statistically significant.

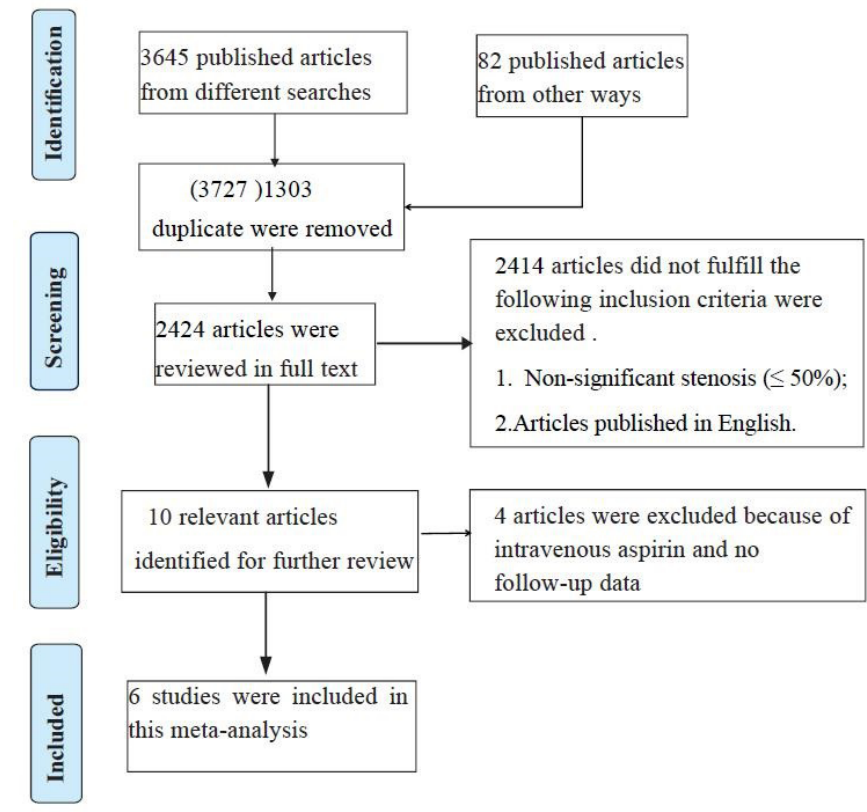

Figure 1 Flow diagram for identification processes.

\section{RESULTS}

\section{Characteristics of included studies}

The search engines were reviewed to identify 3645 related studies, among which 1303 articles were duplicates and 2414 articles did not fulfil the inclusion criteria and were excluded from the study. After removing these studies, four propensity-matched cohorts, ${ }^{11} 131416$ one retrospective analysis ${ }^{12}$ and one prospective multicentre cohort ${ }^{15}$ (figure 1), including a total of 3661 patients (aspirin group, n=1695; no aspirin group, $n=1966$, table 1) were included in the study. Four studies underwent coronary provocation test, except for one study (Seong-Sik Cho, 2019) that used the electrocardiograph provocation test. All studies provided a primary endpoint, with follow-up durations ranging from 1 to 5 years (table 2).

\section{Primary and secondary endpoints}

No significant correlation was recorded between aspirin use and MACE incidence within the follow-up of 1-5 years (combined $\mathrm{OR}=0.90,95 \%$ CI: 0.55 to $1.68, \mathrm{p}=0.829$, $\mathrm{I}^{2}=82.2 \%$ (figure 2 ); subgroup analysis: $\mathrm{OR}=0.89,95 \% \mathrm{CI}$ : 0.40 to $2.02, \mathrm{I}^{2}=86.9 \%$ and $\mathrm{OR}=1.09,95 \%$ CI: 0.81 to 1.47 , $\mathrm{I}^{2}=0 \%$ (figure $\left.3 \mathrm{~A}, \mathrm{~B}\right)$ ).

MI was reported in four studies, and cardiac death was reported in five studies for the secondary endpoint. No significant difference was found between aspirin use and the incidence of MI (OR=0.62, 95\% CI: 0.09 to 4.36, $\left.\mathrm{p}=0.615, \mathrm{I}^{2}=73.8 \%\right)$ or cardiac death $(\mathrm{OR}=1.73,95 \% \mathrm{CI}$ : 0.61 to $4.94, \mathrm{p}=0.444, \mathrm{I}^{2}=0 \%$ ) during the follow-up (figure 4).

\section{Risk of bias assessment and heterogeneity analysis}

The NOS scores for study quality assessment of the included studies ranged from 7 to 9 (table 3). Publication bias is presented by asymmetry in the funnel plot (figure 5). Between-study heterogeneity in MACE-related 
Table 1 Clinical characteristics of patients in included studies

\begin{tabular}{|c|c|c|c|c|c|c|}
\hline $\begin{array}{l}\text { Characteristics } \\
\text { aspirin vs no }\end{array}$ & $\mathrm{Kim}^{12}$ & Ishii $^{14}$ & $\operatorname{Lim}^{13}$ & Lee $^{11}$ & Cho $^{15}$ & Mori $^{16}$ \\
\hline $\begin{array}{l}\text { Age } \\
\text { (year) }\end{array}$ & / & $\begin{array}{l}66.0 \pm 9.5 \text { vs } \\
67.0 \pm 8.4, p=0.428\end{array}$ & $\begin{array}{l}49.0-62.0 \text { vs } \\
49.0-62.5 \\
p=0.61\end{array}$ & $\begin{array}{l}51.3 \pm 6.7 \text { vs } \\
50.8 \pm 7.5 \\
p=0.70\end{array}$ & $\begin{array}{l}57.2 \pm 11.2 \text { vs } \\
53.5 \pm 11.3 \\
p=0.001\end{array}$ & $\begin{array}{l}65.4 \pm 9.9 \text { vs } \\
66.7 \pm 10.3 \\
p=0.07\end{array}$ \\
\hline $\begin{array}{l}\text { Males, } \\
\mathrm{n}(\%)\end{array}$ & / & $\begin{array}{l}47(42.0) \text { vs } 47 \\
(42.0) \\
p=1.000\end{array}$ & $\begin{array}{l}359(82.7) \text { vs } 243 \\
(84.7) \\
p=0.49\end{array}$ & $\begin{array}{l}60(78) \text { vs } 55 \\
(71) \\
p=0.354\end{array}$ & $\begin{array}{l}412(64.3) \text { vs } 590 \\
(58.4) \\
p=0.055\end{array}$ & $\begin{array}{l}247(73.7 \%) \\
\text { vs } 253 \\
(75.5 \%) \\
p=0.66\end{array}$ \\
\hline $\begin{array}{l}\text { Hypertension, } \\
\mathrm{n}(\%)\end{array}$ & / & $\begin{array}{l}52(46.4) \text { vs } 57 \\
(50.9) \\
p=0.504\end{array}$ & $\begin{array}{l}156(36.0) \text { vs } 104 \\
(36.2), p=0.96\end{array}$ & $\begin{array}{l}22(29) \text { vs } 20 \\
(26) \\
p=0.717\end{array}$ & $\begin{array}{l}294(45.9) \text { vs } 320 \\
(31.7) \\
p=0.001\end{array}$ & $\begin{array}{l}158(47.2 \%) \\
\text { vs } 166 \\
(49.6 \%) \\
p=0.59\end{array}$ \\
\hline $\begin{array}{l}\text { Diabetes mellitus, } \\
\mathrm{n}(\%)\end{array}$ & I & $\begin{array}{l}26(23.2) \text { vs } 27 \\
(24.1) \\
p=0.875\end{array}$ & $\begin{array}{l}98(22.6) \text { vs } 66 \\
(23.0) \\
p=0.91\end{array}$ & $\begin{array}{l}17(22) \text { vs } 16 \\
(19) \\
p=0.547\end{array}$ & $\begin{array}{l}73(11.4) \text { vs } 83 \\
(8.2) \\
p=0.037\end{array}$ & $\begin{array}{l}56(16.7 \%) \text { vs } \\
56(16.7 \%), \\
p=1.00\end{array}$ \\
\hline $\begin{array}{l}\text { Dyslipidaemia, } \\
\text { n (\%) }\end{array}$ & I & $\begin{array}{l}62(55.4) \text { vs } 60 \\
(53.6) \\
p=0.788\end{array}$ & $\begin{array}{l}91(21.0) \text { vs } 62 \\
(21.6) \\
p=0.84\end{array}$ & / & $\begin{array}{l}98(15.4) \text { vs160 } \\
(15.8) \\
p=0.800\end{array}$ & $\begin{array}{l}156(46.6 \%) \\
\text { vs } 142 \\
(42.4 \%) \\
p=0.31\end{array}$ \\
\hline $\begin{array}{l}\text { Ca channel blocker, } \\
\text { n (\%) }\end{array}$ & I & $\begin{array}{l}104(92.9) \text { vs } 101 \\
(90.2) \\
p=0.472\end{array}$ & $\begin{array}{l}420(96.9) \text { vs } 275 \\
(95.8), p=0.46\end{array}$ & $\begin{array}{l}50(65) \text { vs } 48 \\
(62) \\
p=0.738\end{array}$ & $\begin{array}{l}152(24.2) \text { vs } 162 \\
(16.12) \\
p=0.001\end{array}$ & $\begin{array}{l}316(94.3 \%) \\
\text { vs } 313 \\
(93.4 \%) \\
p=0.75\end{array}$ \\
\hline $\begin{array}{l}\text { Beta-blocker, } \\
\mathrm{n}(\%)\end{array}$ & I & $\begin{array}{l}6(5.4) \text { vs } 7 \text { (6.3), } \\
p=0.775\end{array}$ & $\begin{array}{l}1(0.2) \text { vs } 0(0.0) \\
p=0.48\end{array}$ & $\begin{array}{l}17(22) \text { vs } 23 \\
(30), \\
p=0.270\end{array}$ & $\begin{array}{l}54(8.65) \text { vs } 59 \\
(5.88) \\
p=0.065\end{array}$ & I \\
\hline
\end{tabular}

ACEI/ARB, angiotensin-converting enzyme inhibitor/angiotensin receptor blocker.

research was $82.2 \%$ and $86.9 \%$. Therefore, the outcome of subgroup analyses of $\mathrm{I}^{2}$ was $0 \%$, indicating low publication bias (figure 3). The between-study heterogeneities in MI and cardiac death-related studies were $73.8 \%$ and $0 \%$, respectively, indicating the occurrence of high publication bias for the MI endpoint (figure 4).

\section{DISCUSSION}

Our meta-analysis showed that aspirin had no significant effect on reducing MACE, MI and cardiac death in VSA patients without significant stenosis.

Coronary artery spasm (CAS) has been reported to play a significant role in the pathogenesis of ischaemic heart disease, including acute coronary syndrome and chronic coronary syndrome. ${ }^{17}$ A common mechanism by which MI or MINOCA manifests is platelet aggregation, which leads to coronary thrombus formation. Aspirin inhibits cyclooxygenase- 1 by reducing the production of thromboxane A2 and therefore has been extensively used in primary or secondary prevention of thrombosis among patients with atherosclerosis or coronary artery disease. ${ }^{18} 19$ However, the benefit of low dosage aspirin in primary prevention was counterbalanced by higher rates of treatment-related adverse events. ${ }^{78}$ Earlier studies have shown that aspirin use can aggravate CAS due to the lowered production of thromboxane A2 and increased MACE incidence in VSA patients. ${ }^{2021}$ Thus, the use of aspirin in VSA patients remains controversial.

MACE incidence in patients administered low-dose aspirin was significantly higher than that among patients 


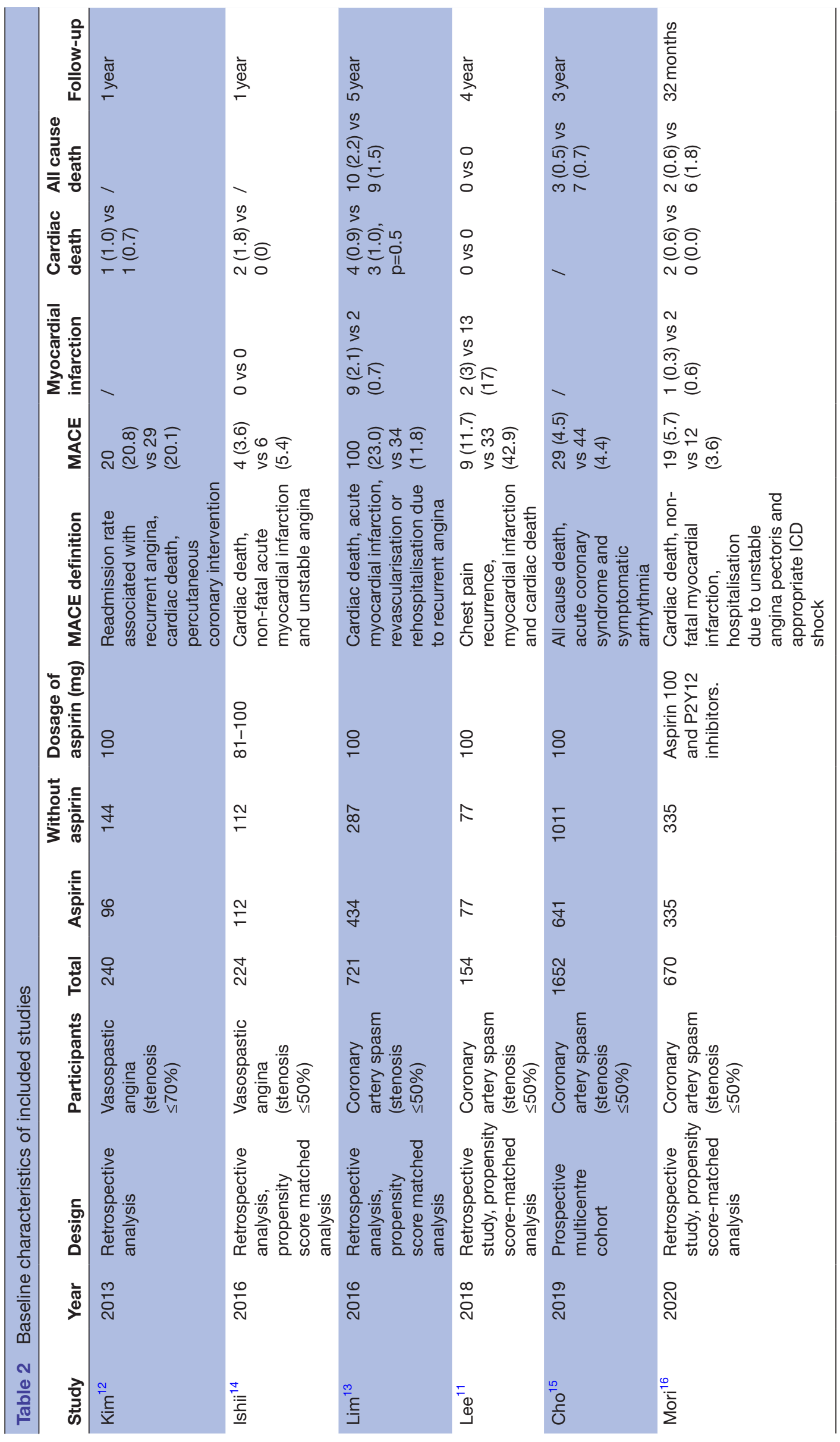

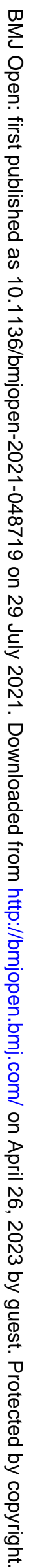




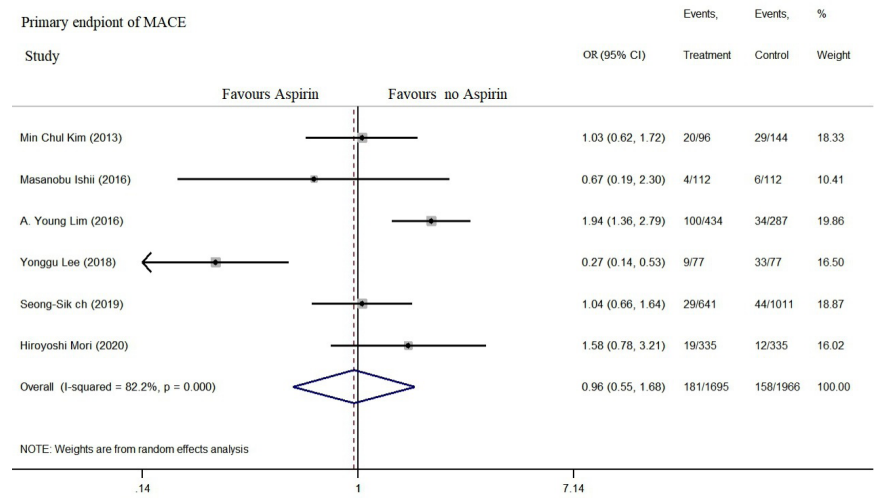

Figure 2 Aspirin use is not associated with a low incidence of MACE in patients with VSA. MACE, major cardiovascular adverse events; VSA, vasospastic angina.

not administered aspirin (HR (HR)=1.54; CI: 1.04 to 2.28; $\mathrm{p}=0.037$ ) during a 52-month median follow-up period. ${ }^{13}$ In contrast, MI ( $\mathrm{HR}=0.13$; CI: 0.03 to $0.61 ; \mathrm{p}=0.014)$ and chest pain recurrence (HR=0.29; CI: 0.12 to 0.71 ; $\mathrm{p}=0.006$ ) were observed by Lee $e t$ al to have been significantly reduced by aspirin use among VSA patients during follow-up. ${ }^{11}$ Lee et al showed that acute intimal tears and erosion identified by optical coherence tomography are susceptible to thrombosis leading to MI. Therefore, aspirin was evidenced to reduce adverse events in VSA patients with a greater number of thrombotic intracoronary lesions. Nevertheless, aspirin use was not significantly correlated with the occurrence of cardiovascular events among VSA patients with non-significant stenosis during a

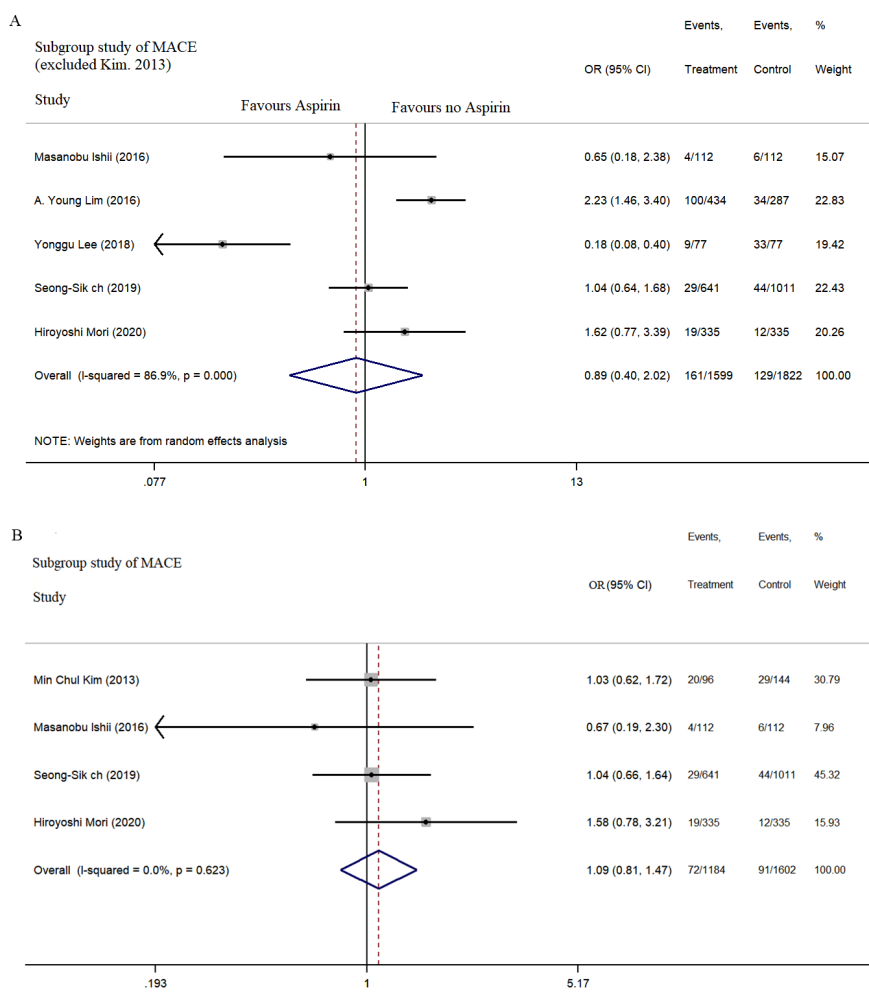

Figure 3 Subgroup analysis of MACE with aspirin use in patients with VSA. MACE, major cardiovascular adverse events; VSA, vasospastic angina.
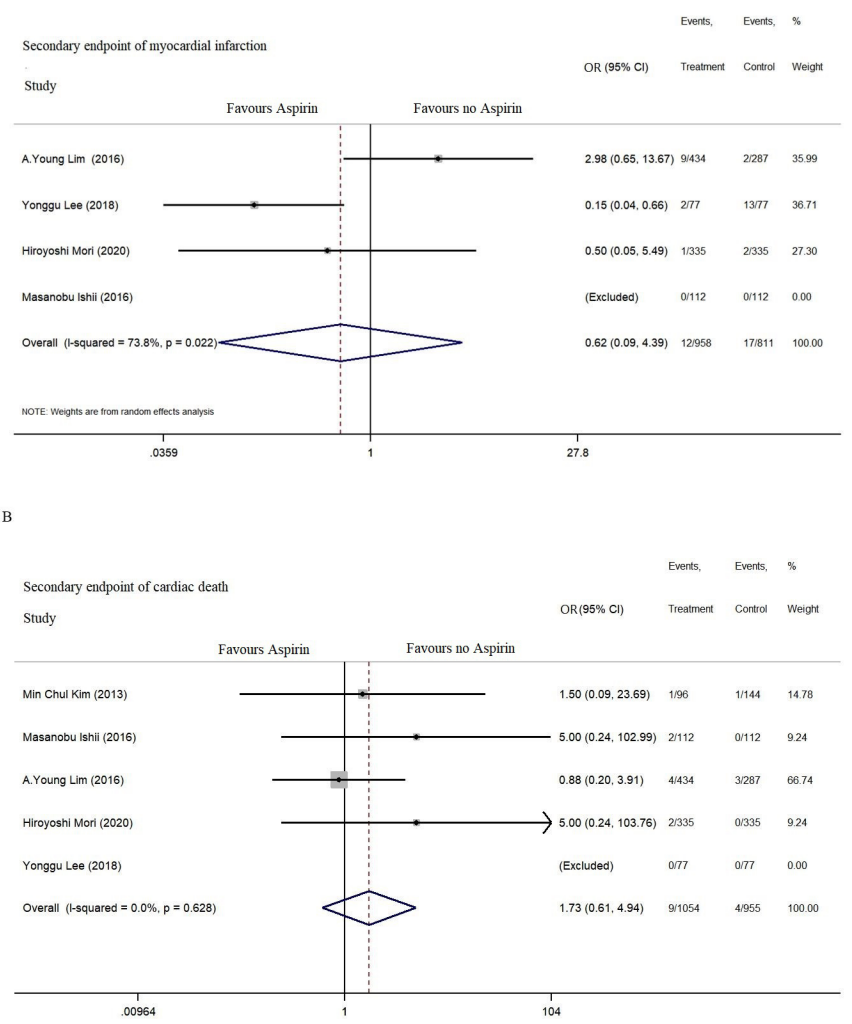

Figure 4 Secondary endpoints including myocardial infarction, cardiac death and all-cause death during 1-5 years of follow-up.

49-month mean follow-up period $(\mathrm{p}=0.541) .{ }^{14}$ Moreover, the aspirin-treated group exhibited a similar MACE incidence compared with the non-antiplatelet agent group ( $\mathrm{HR}=0.96$; CI: 0.59 to $1.55, \mathrm{p}=0.872$ ) as reported by Cho et $a l .{ }^{15}$ Antiplatelet therapy was recently shown by Mori $e t$ $a l$ to have no beneficial effects on MACE ( $5.7 \%$ vs $3.6 \%$, $\mathrm{p}=0.20$ ) among VSA patients during a 32-month median follow-up period. ${ }^{16}$

Our meta-analysis indicates that aspirin use may not be linked to a lower risk of MACE and cardiac death. The subgroup analysis of MACE indicated that the studies by Lee ${ }^{11}$ and $\operatorname{Lim}^{13}$ were heterogeneous. The origin of heterogeneity in these studies may be attributable to chest pain recurrence in the MACE, which results in an entirely different outcome due to the definition. The following may potentially explain the lack of beneficial effects of aspirin use: (i) Aspirin use is known to damage the gastric mucosal barrier and increase risk of erosions, ulcers and bleeding by inhibiting cyclooxygenase-1 enzyme activity. ${ }^{22}$ Several meta-analyses have indicated that aspirin's efficacy in primary prevention of cardiovascular disease should be weighed against any increase in major bleeding. ${ }^{23-25}$ (ii) The adverse effects of asthma and dyspnoea may lead to CAS and increase the occurrence of MACE or cardiogenic death with aspirin use. ${ }^{26} 27$ (iii) The synthesis of prostacyclin, a well-known vasodilator released by endothelial cells, is inhibited by aspirin ${ }^{28}$ and CAS is induced 


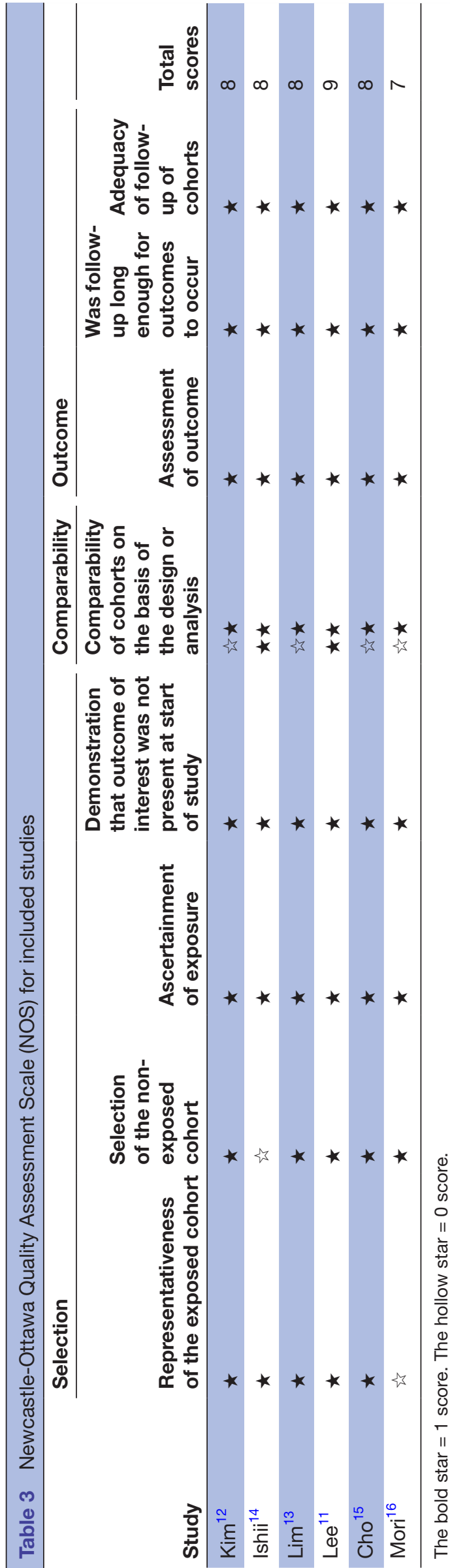

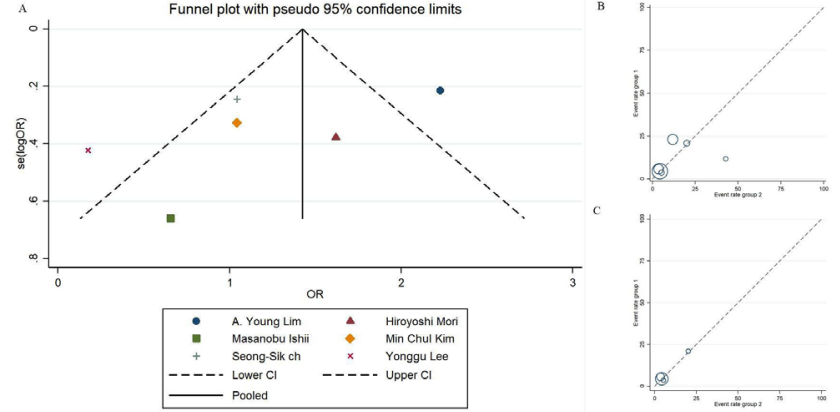

Figure 5 Assessment of bias risk of the studies.

by aspirin. This could, in turn, cause recurrent angina leading to rehospitalisation, MI, and cardiac death.

We found that aspirin use may have a protective effect against MI, which may be explained by aspirin's pharmacological mechanism. However, there was high heterogeneity in the study, which may be attributed to the lack of related studies and a different definition of MI used by Mori et al. ${ }^{16}$ Aspirin use in CAS patients can be both advantageous and disadvantageous. Further investigation is necessary to determine when to recommend aspirin use.

Several potential limitations should be considered in this meta-analysis. First, MACE and MI were defined differently in the included articles. Due to the lack of original data, no standard definition of MACE was accessible in this meta-analysis. Second, one study by Mori et $a l^{16}$ showed that an antiplatelet drug containing both aspirin and P2Y12 inhibitors was used as the treatment strategy. Third, the sample size in this analysis is too small; only a few studies conducted propensity matching analysis to balance baseline characteristics. The limitations inherent to multicentre observational studies performed in both retrospective and prospective manners could not be avoided in this analysis. Fourth, patients with $40 \%$ stenosis are considered to have VSA without coronary stenosis but might benefit from aspirin. Subgroup analysis should be performed in the next study. Finally, the major bleeding outcome was excluded from this study, which is essential for understanding the advantages of antiplatelet therapy. Despite these limitations, the merit of this study is that it is the first to evaluate the prognosis of VSA patients using low-dose aspirin.

\section{CONCLUSIONS}

Aspirin use may not reduce the risk of cardiovascular events in VSA patients without significant stenosis. Owing to its potential adverse effects, regular use of aspirin in VSA patients without significant stenosis should involve a thoughtful discussion.

\section{Author affiliations}

${ }^{1}$ Department of Cardiology, Shenzhen Cardiovascular Minimally Invasive Medical Engineering Technology Research and Development Center, Shenzhen People's Hospital, Second Clinical Medical College of Jinan University, First affiliated Hospital of South University of Science and Technology, Shenzhen, China 
${ }^{2}$ School of Pharmacy, Guangdong Medical University, Dongguan 523808, Guangdong, China

${ }^{3}$ Department of Health Management, Shenzhen People's Hospital, Second Clinical Medical College of Jinan University, First affiliated Hospital of South University of Science and Technology, Shenzhen, China

${ }^{4}$ Department of Pharmacy, Shenzhen People's Hospital, Second Clinical Medical College of Jinan University, First affiliated Hospital of South University of Science and Technology, Shenzhen, China

Contributors YL, QC and HYQ conceived, designed and led the study. YL, YC, JY and SD investigated, conducted the study and collected data. YL, SD and QC wrote, revised and edited the manuscript. All authors supervised the study and approved the final version of the manuscript.

Funding This study was supported by a grant from the Shenzhen Key Medical Discipline Construction Fund (No. SZXK003 and No. SZXK059) and Sanming Project of Medicine in Shenzhen (No. SZSM201412012).

Competing interests None declared.

Patient and public involvement Patients and/or the public were not involved in the design, or conduct, or reporting or dissemination plans of this research.

Patient consent for publication Not required

Ethics approval The institutional review board at the Shenzhen People's Hospital approved the study protocol.

Provenance and peer review Not commissioned; externally peer reviewed.

Data availability statement All data relevant to the study are included in the article or uploaded as supplementary information.

Open access This is an open access article distributed in accordance with the Creative Commons Attribution Non Commercial (CC BY-NC 4.0) license, which permits others to distribute, remix, adapt, build upon this work non-commercially, and license their derivative works on different terms, provided the original work is properly cited, appropriate credit is given, any changes made indicated, and the use is non-commercial. See: http://creativecommons.org/licenses/by-nc/4.0/.

ORCID iDs

Yaowang Lin http://orcid.org/0000-0002-4075-4259

Haiyan Qin http://orcid.org/0000-0002-1057-4003

Qiuling Chen http://orcid.org/0000-0003-0565-8082

\section{REFERENCES}

1 Montone RA, Niccoli G, Fracassi F, et al. Patients with acute myocardial infarction and non-obstructive coronary arteries: safety and prognostic relevance of invasive coronary provocative tests. Eur Heart J 2018;39:91-8.

2 Kunadian V, Chieffo A, Camici PG, et al. An EAPCI Expert Consensus Document on Ischaemia with Non-Obstructive Coronary Arteries in Collaboration with European Society of Cardiology Working Group on Coronary Pathophysiology \& Microcirculation Endorsed by Coronary Vasomotor Disorders International Study Group. Eur Heart J 2020;41:3504-20.

3 Lee B-K, Lim H-S, Fearon WF, et al. Invasive evaluation of patients with angina in the absence of obstructive coronary artery disease. Circulation 2015;131:1054-60.

4 Khuddus MA, Pepine CJ, Handberg EM, et al. An intravascular ultrasound analysis in women experiencing chest pain in the absence of obstructive coronary artery disease: a substudy from the National heart, lung and blood Institute-Sponsored women's ischemia syndrome evaluation (wise). J Interv Cardiol 2010;23:511-9.

5 Knuuti J, Wijns W, Saraste A, et al. 2019 ESC guidelines for the diagnosis and management of chronic coronary syndromes. Eur Heart J 2020;41:407-77.

6 Collet J-P, Thiele H, Barbato E. The 'Ten Commandments' for the 2020 ESC Guidelines for the management of acute coronary syndromes in patients presenting without persistent ST-segment elevation. Eur Heart J 2020;41:3495-7.
7 ASCEND Study Collaborative Group, Bowman L, Mafham M, et al. Effects of aspirin for primary prevention in persons with diabetes mellitus. N Engl J Med 2018;379:1529-39.

8 Gaziano JM, Brotons C, Coppolecchia R, et al. Use of aspirin to reduce risk of initial vascular events in patients at moderate risk of cardiovascular disease (arrive): a randomised, double-blind, placebocontrolled trial. Lancet 2018;392:1036-46.

9 Guirguis-Blake JM, Evans CV, Senger CA, et al. Aspirin for the primary prevention of cardiovascular events: a systematic evidence review for the U.S. preventive services Task force. Ann Intern Med 2016;164:804-13.

10 Zheng SL, Roddick AJ. Association of aspirin use for primary prevention with cardiovascular events and bleeding events: a systematic review and meta-analysis. JAMA 2019;321:277-87.

11 Lee Y, Park H-C, Shin J. Clinical efficacy of aspirin with identification of intimal morphology by optical coherence tomography in preventing event recurrence in patients with vasospasminduced acute coronary syndrome. Int $J$ Cardiovasc Imaging 2018;34:1697-706.

$12 \mathrm{Kim}$ MC, Ahn Y, Park KH, et al. Clinical outcomes of low-dose aspirin administration in patients with variant angina pectoris. Int $\mathrm{J}$ Cardiol 2013;167:2333-4.

13 Lim AY, Park TK, Cho SW, et al. Clinical implications of low-dose aspirin on vasospastic angina patients without significant coronary artery stenosis; a propensity score-matched analysis. Int J Cardiol 2016;221:161-6.

14 Ishii M, Kaikita K, Sato K, et al. Impact of aspirin on the prognosis in patients with coronary spasm without significant atherosclerotic stenosis. Int J Cardiol 2016;220:328-32.

15 Cho S-S, Jo S-H, Han SH, et al. Clopidogrel plus aspirin use is associated with worse long-term outcomes, but aspirin use alone is safe in patients with vasospastic angina: results from the VA-Korea registry, a prospective multi-center cohort. Sci Rep 2019;9:17783.

16 Mori H, Takahashi J, Sato K, et al. The impact of antiplatelet therapy on patients with vasospastic angina: a multicenter registry study of the Japanese coronary spasm association. Int J Cardiol Heart Vasc 2020;29:100561.

17 Yasue H, Mizuno Y, Harada E. Coronary artery spasm - Clinical features, pathogenesis and treatment. Proc Jpn Acad Ser B Phys Biol Sci 2019;95:53-66.

18 Capodanno D, Alfonso F, Levine GN, et al. ACC/AHA Versus ESC Guidelines on Dual Antiplatelet Therapy: JACC Guideline Comparison. J Am Coll Cardiol 2018;72:2915-31.

19 Valgimigli M, Bueno H, Byrne RA, et al. 2017 ESC focused update on dual antiplatelet therapy in coronary artery disease developed in collaboration with EACTS: the task force for dual antiplatelet therapy in coronary artery disease of the European Society of cardiology (ESC) and of the European association for Cardio-Thoracic surgery (EACTS). Eur Heart J 2018;39:213-60.

20 Picard F, Sayah N, Spagnoli V, et al. Vasospastic angina: a literature review of current evidence. Arch Cardiovasc Dis 2019;112:44-55.

21 Miwa K, Kambara H, Kawai C. Effect of aspirin in large doses on attacks of variant angina. Am Heart J 1983;105:351-5.

22 Iwamoto J, Saito Y, Honda A, et al. Clinical features of gastroduodenal injury associated with long-term low-dose aspirin therapy. World J Gastroenterol 2013;19:1673-82.

23 Antithrombotic Trialists' (ATT) Collaboration, Baigent C, Blackwell $\mathrm{L}$, et al. Aspirin in the primary and secondary prevention of vascular disease: collaborative meta-analysis of individual participant data from randomised trials. Lancet 2009;373:1849-60.

24 Xie W, Luo Y, Liang X, et al. The efficacy and safety of aspirin as the primary prevention of cardiovascular disease: an updated metaanalysis. Ther Clin Risk Manag 2019;15:1129-40.

25 Whitlock EP, Burda BU, Williams SB, et al. Bleeding risks with aspirin use for primary prevention in adults: a systematic review for the U.S. preventive services Task force. Ann Intern Med 2016;164:826-35.

26 Hangouche AJE, Lamliki O, Oukerraj L, et al. Kounis syndrome induced by oral intake of aspirin: case report and literature review. Pan Afr Med J 2018;30:301.

27 Shah NH, Schneider TR, DeFaria Yeh D, et al. EosinophiliaAssociated coronary artery vasospasm in patients with AspirinExacerbated respiratory disease. J Allergy Clin Immunol Pract 2016;4:1215-9

28 Bates ER, Lau WC. Controversies in antiplatelet therapy for patients with cardiovascular disease. Circulation 2005;111:e267-71. 